\title{
Industrial revolution 4.0 in industrial laundries and their information technologies landscape
}

\author{
Martin Polívka ${ }^{1, *}$, and Lilia Dvořáková ${ }^{1}$ \\ ${ }^{1}$ University of West Bohemia in Pilsen, Department of Finance and Accounting, Univerzitní 8, \\ 30100, Pilsen, Czech Republic
}

\begin{abstract}
This paper presents the research results in the field of implementation of fourth industrial revolution technologies into the service sector, with a specific focus on the integration of Industry 4.0 technologies into corporate processes of industrial laundries. The theme covered was found topical following the analysis of practical needs and based on the specific nature of industrial laundry processes and only marginal interest paid in professional theory and discussions to the possibility and efficiency of the Industry 4.0 technologies implementation into non-production companies. Based on the analysis and evaluation of secondary data, advanced Industry 4.0 technologies have been identified which might lead to the increase of industrial laundries efficiency. Further, the methods of monitoring, structured interview and case study have been combined to design the integration of Industry 4.0 technologies into the system of existing information and communication technologies and systems. Based on a quality comparison, the case study and structured interview results have proven the benefits of implementation of automated identification and data collection technologies including the implementation of vertical integration of corporate information system and horizontal integration leading to the interconnection with customers in industrial laundries corporate processes.
\end{abstract}

\section{Introduction}

The current professional literature mentions frequently that this is the era of the fourth industrial revolution, sometimes also called the "Revolution 4.0" (see more e.g. in [1] , [2], [3]). The first industrial revolution dates back to the late $18^{\text {th }}$ and early $19^{\text {th }}$ centuries and it was linked to the invention of a steam engine, the second industrial revolution dates back to the early $20^{\text {th }}$ century and it was linked to the development of production lines and power engineering and the third industrial revolution started in the 1970's due to development of information technologies and computer-controlled manufacturing; the current extremely rapid development of information and communication technologies, Internet of Things and other modern technologies, such as additive production, system integration, artificial intelligence, virtual reality etc., are considered to be the makers of the fourth industrial revolution. Although many of these technologies are not really new (for example, EDI technology which still plays an important role in system integration dates back to the 1970's), the mass spreading of these technologies enabled by an ever-increasing performance of standardly available IT equipment and their mutual integration clearly brings the potential of large changes in many industries. Therefore, in 2011 at the Hannover fair, the term Industry 4.0 [4] was presented as a designation of an industrial sector of the

\footnotetext{
* Corresponding author: polivkam@kfu.zcu.cz
} 
future in which these modern technologies will be integrated. This term promptly became largely discussed both in the academic circles and in practice (see [5], [6]).

Soon, efforts to implement the fourth industrial revolution technologies in other economic areas emerged, gradually giving rise to the concepts like "Services 4.0" [7], "Agriculture 4.0" [8], "Healthcare 4.0" [9], "Logistics 4.0" [10], or, respectively at the general level "Society 4.0", or also "Society 5.0" [11]. However, the fourth industrial revolution is still generally seen as a phenomenon which will affect mostly production companies; you can find the proof in a number of professional studies covering these issues. For example, as at 22 February 2020, in the quotation database Scopus, total 1577 entries were found containing the combination of key words "Industry 4.0" and „Manufacturing," while there were only 32 entries containing the key word "Logistics 4.0", 19 entries containing "Agriculture 4.0," 15 entries for "Healthcare 4.0" and 5 for "Services 4.0". A similar disproportion among studies covering the fourth industrial revolution in production and other industries applies also in full-text scientific databases such as Science Direct or SpringerLink. So far, only a marginal interest has been paid to the possible implementation of fourth industrial revolution technologies into non-production companies in professional discussions. The objective of this paper is therefore to fill in this gap in the present state of knowledge.

\section{Research scope and methods}

This paper presents the result of research of potential and real implementation of the fourth industrial revolution into industrial laundry environment, or rather into its information system. The research objective was firstly to assess which technologies considered to be a part of the fourth industrial revolution might make the industrial laundry operation more efficient. The second research objective was to design how to implement these fitting technologies into the laundry's physical operation and how to integrate them into its IT landscape, i.e. into the set of information and communication technologies and systems (see more in [12]). Laundry operation was chosen for the analysis mainly because one of the authors of this paper has been practically involved with the industry technologies for a long time and has current knowledge of practical needs of companies in the industry. Also, it is an interesting industry which, although a part of the service sector, has many elements of industrial companies owing to its character (the size of operations and quantity of machine equipment, high automation level, demanding for materials and powers).

A combination of desk research, monitoring, structure interviews and case study methods was chosen as a research method. Based on studying the literature and other resources, individual Industry 4.0 technologies were first identified and assessed as to their appropriateness for increasing the laundry operation efficiency. Then, a case study was prepared, showing the existing solutions for industrial laundries using any of these technologies, and its impacts were assessed. The subsequent discussion then covers potential extension of the existing solution by other fourth industrial revolution technologies.

\section{Results}

\subsection{Technologies of Industry 4.0}

Although considerable attention is currently being paid to the issues of the fourth industrial revolution and Industry 4.0, it has not been clearly specified what exactly these terms mean 
- as stated in [13], the term "Industry 4.0 " is currently subject to inflation and it is present almost everywhere, without its content having been clearly described and structured. Trying to capture the term, professional literature usually uses either the Reference Architecture Model Industrie 4.0 (abbreviated as RAMI 4.0), or an exhaustive list of technologies which should be subject to it - see e.g. [2, page $26-27$ ], [4] or [14].

In the RAMI 4.0 model, the conception of Industry 4.0 is described rather generally and its objective is to create a structured aid usable for the purpose of considerations of its introduction in a company [15]. For the purposes of a more practically oriented analysis of the elements of Industry 4.0 which are capable of being implemented into the laundry operation, it is therefore more suitable to use its definition based on the list of particular technologies. The following nine basic technologies covered by the conception of Industry 4.0, frequently referred to also as its "9 pillars" [16] are considered to be:

\section{Big data}

2. Autonomous, mainly collaborative robots

3. Simulations

4. System integration, in the form of Horizontal, Vertical or End-to-end integrations

5. Internet of Things (referred to also as IoT)

6. Cyber-Physical Systems (referred to also as CPS)

7. Cloud technologies

8. Additive production

9. Extended reality

Based on an analysis made in the publication [6], we believe it is appropriate adding a tenth technology, currently playing an irreplaceable part in the current corporate practice, to these "9 pillars of Industry 4.0", the contents of which are described in more detail in the referenced literature:

10. Automatic identification and data capture (referred to also as AIDC).

This term contains a set of technologies which allow for object identification, followed by automated capture and storage of data on the objects. For these purposes, a wide spectrum of methods is currently being used, most of which are based on an initial labeling of a monitored object by a machine-readable identifier, followed by reading of the identifier including but not limited to labeling with bar codes or QR codes and also radio frequency identification (usually abbreviated as RFID) which is based on the principle of information transmission using radio waves. Some methods such as machine recognition of audio or video do not use any identifiers.

\subsection{Process improvement in the industrial laundry}

In this section, the potential of individual Industry 4.0 technologies to make the industrial laundry operation more effective will be assessed. Industrial laundry activities involve washing laundry for corporate clients such as industrial companies, hospitals or hotels. For these activities, several specifics are characteristic:

- It is a large-volume operation and hundreds of pieces of laundry may pass through an industrial laundry, depending on its size. Industrial laundry operation has also high demands for fixed capital in the form of machine equipment which capacity should be therefore sufficiently utilized.

- $\quad$ Pieces of laundry keep circulating between the customer and the industrial laundry. A certain piece of laundry does not necessarily need to be reserved for a particular customer only - in some cases (unless the piece of laundry is personified, e.g. using a sewn $\operatorname{logo}$ ), a specific piece of laundry may be delivered to a different customer after each washing. This applies mainly for such laundry where size is not the issue, such as 
pillow cases, sheets etc. (the term "flat laundry" is often used to describe these types of laundry).

- Individual pieces of laundry of the same type may not be visually told apart from one another.

These specifics make it practically impossible to keep manual records of laundry containing a sufficient extent of information about each piece of laundry and being sufficiently reliable at the same time. This leads to a situation that the laundry operation works as a "black box" into which laundry accepted from customers enter on one end, being characterized only by the number of pieces of individual types of laundry, and similarly, dispatches of laundry to the customers exit on the other end. Particular pieces of laundry are not identified or recorded in such a system which results in the following problems:

- It is not possible to trace the location of a particular piece of laundry at a given time, whether it is at the customer's or in the industrial laundry. It means that if pieces of laundry are lost, it is not possible to tell where they were lost and whether it is the customer or the laundry that is responsible for the loss.

- No information as to how long a particular piece of laundry has been in the laundry or at the customer is available. Also, the number of washing cycles to which any particular piece of laundry has been subjected is not recorded in any way. This might present a problem in terms of the operation efficiency and also in case that the age or number of washing cycles should be controlled from legislative reasons (such as for protective working aids).

- It is even not possible to detect reliably when a piece of laundry gets completely out of circulation, either permanently (e.g. as a result of theft) or temporarily (when a piece of laundry gets temporarily lost at the customer) because individual pieces are not identifiable.

The severity of these problems is even increased by the fact that the industrial laundry often does not only provide the washing service to its customers but it rents the linen or clothes which are in such case owned by the industrial laundry that is bound to deliver the determined quantities of clean and undamaged laundry to the customer on the agreed dates. The industrial laundry's capital is thus allocated in assets over which it has almost no control because of the above-described specifics. Incorrect records and losses of pieces of laundry make it necessary for the industrial laundry to keep more pieces of laundry (and capital bound in it) for each customer than it would be otherwise necessary.

In regard to the above-described specifics and problems, making the laundry operating processing more effective means in particular:

1. Making laundry tracing records more extensive and accurate. This change should result in the laundry workers being able to trace the relevant data for each piece of laundry at any moment (such as age, number of washing cycles, to whom it is allocated, what is its current location etc.). Ultimately, it should result in the drop of losses of laundry and reduction of the associated costs and in the improvement of communication with customers.

2. Expediting laundry passage through the industrial laundry. This change brings about more expedient order processing, more efficient use of the industrial laundry's fix capital, reduction of the number of operation workers and the associated reduction of salary costs, cutting down of the cash-to-cash cycle and other positive effects.

\subsection{Applicability of "Industry 4.0" technologies in industrial laundry}

Based on an analysis of the substance of individual Industry 4.0 technologies, we have identified those which might be used for reaching these objectives: 
- Autonomous collaborative robots. Even today, transporters moving laundry in bags between individual stages of the washing process are being routinely used in industrial laundries. Individual stages are automated, too, using equipment such as tunnel washing machines or finishers. Some operations, such as receipt or dispatch of laundry or moving of laundry from the transporter into particular equipment and back still depend on human work, although these are often physically demanding tasks. Modern autonomous robots able to work in a changing environment could replace human workers in these activities, or operate together with them, and this should lead to expediting the passage of laundry through the industrial laundry.

- System integration in all forms as mentioned above. Vertical integration could be used to interconnect the laundry operation control IT system with other systems used in the laundry, such as its ERP system. Horizontal integration might serve for interconnection with the customers' IT systems. Automated data transfer without the need for their repeated manual entries should lead to office labor savings and to expediting the whole process from the order receipt to the issue and accounting for the resulting invoice. End-to-end integration might be used for recording information about a particular piece of laundry during its whole lifecycle; a necessary precondition for such use is that it would be possible to clearly identify each piece.

- Internet of Things and Cyber-Physical Systems. These Industry 4.0 technologies are mentioned together because their potential uses are closely linked together. Connection of all equipment in the laundry into a network would allow for their mutual automated coordination. Communication of all pieces of equipment with the laundry operation control IT system would allow for the creation of a cyber-physical system in which all physical equipment would have their virtual representations and might be controlled centrally, which should minimize downtime and inefficiencies and expedite the passage of laundry through the industrial laundry. A more accurate representation of reality in a virtual environment might be obtained if individual pieces of laundry would be labeled with machine-readable identifiers, thus being incorporated into the cyber-physical system as well.

- Automatic identification and data capture. As already explained in the previous text, precise manual records of particular pieces of laundry are practically unfeasible. Automated identification of pieces of laundry is a precondition for keeping these records. Automated data capture should also lead to significantly expediting the receipt and dispatch of laundry because it would eliminate the need to manually count the received or dispatched pieces.

These five technologies were thus assessed as appropriate for making the industrial laundry operation more effective. As far as the remaining Industry 4.0 technologies are concerned, their use in the industrial laundry is certainly possible, perhaps except for additive production (for example, some IT systems might be placed in a cloud instead in local devices, big data analysis or use of simulations for ergonomic optimization of the laundry), however, it would not be directly related to operating issues.

\subsection{Case study}

To prepare a case study, an industrial laundry with more than 200 employees was selected, being one of the largest companies of this type in the Czech Republic (based on EU classification, however, it is a medium-size enterprise). The enterprise provides services to different types of companies such as industrial enterprises, hospitals or hotels (i.e. B2B segment) mainly by means of renting the linen and clothes, including both flat linen and personal clothes. 
For the sake of expediting the passage of laundry through the industrial laundry and precise records and traceability of individual pieces of laundry across its whole lifecycle, the enterprise implemented a project involving introduction of several Industry 4.0 technologies. The project was based on combining the following technologies:

- $\quad$ IT system for laundry operation control.

- $\quad$ Labeling each piece of laundry using RFID UHF chip which allows for automated data capture and processing.

- $\quad$ System integration of laundry IT system with other software.

In the laundry operation control IT system, operation data such as receipts, dispatches or repairs of laundry are recorded and individual orders are created and monitored in the system. It is in fact a specific version of an MES (Manufacturing Execution System). The IT system has a two-layer architecture where the database common for both establishments is located on a server and client applications on individual working stations. A unique identifier has been allocated to each piece of laundry, which allows the system to keep accurate records of its current status - age, number of washing cycles, current location (in the laundry or with a particular customer), and in case of personal clothes, the person to whom they are currently allocated.

Data capture is automated - individual pieces of laundry are not counted manually at their receipt or dispatch but they are read using antennas and UHF readers. These devices are able to read hundreds of chips per second and the data read are transmitted via serial port interface into the IT system where they are further processed. As reading dirty laundry at the receipt is less reliable because of higher humidity, two-level reading is in place at the receipt - the laundry first goes through the reading portal at the entry into the industrial laundry and then, it is read again by devices placed over each washing machine. This measure allows for reliability of even the entry reading of more than $99 \%$; the exit reading has similar reliability with single-layer reading only as the laundry is dry and folded.

Laundry control IT system is connected to other system, using system integration. The first of these systems is ERP into which supporting materials for invoicing are exported in the form allowing for an immediate issue and accounting for an invoice.

Laundry control system is also connected to a web application available on the Internet, which is used by corporate customers for ordering linen and clothes. In this application, customers may enter the types and quantities of clean laundry which they request at the next delivery and at the same time, they are able to see how many pieces of laundry of each type they currently have from the laundry and how many they can still order, based on their current contract.

The last software with which the laundry control system is integrated is a mobile application operated on industrial portable terminals equipped with UHF chip readers. Mobile readers are used both by the laundry operation employees and by selected customers to whom the laundry lends the readers. The laundry employees use the readers for laundry deliveries to customers to verify that the delivered quantity corresponds with the quantity declared on delivery notes, and also for making periodic inventory-takings of linen and clothes with individual customers. Customers' employees may obtain particular information about each piece of laundry using the readers - e.g. how old is the piece, how many washing cycles it has been in or (in case of personal clothes) the person to whom it has been allocated.

As far as the case study assessment is concerned, the studied industrial laundry does not have any statistics available which would allow for quantifying the comparison of the state before and after the implementation of the discussed technologies. Based on the results of fifteen structured interviews with the company management and customers and quality comparison with the previous state, the following benefits of implemented technologies have been confirmed: 
- $\quad$ AIDC technology brought a significant expediting of laundry handling because it is no longer necessary to count each piece manually - the laundry is read automatically in bulk within seconds.

- AIDC technology also allowed for creating complete and accurate records of individual pieces of laundry and for their tracing.

- Vertical system integration between the laundry operation control system and ERP resulted in savings of billers' and accountants' work, expediting the invoice issuing and removing any human factor errors resulting from manual data retyping among individual systems.

- Horizontal system integration to the laundry ordering web application simplified and expedited the communication with customers, just like lending mobile terminals to the customers did.

- The use of mobile terminals also lead to making the laundry records and traceability even more precise, it allowed for establishing a double control at laundry deliveries where the pieces of laundry are read both by a stationary antenna and reader in the laundry and at delivery at the customer's by a mobile terminal. Comparison of both results makes sure that laundry does not get lost on the way between the industrial laundry and the customer.

In general, the implementation of laundry control IT system based on AIDC technology, horizontally and vertically integrated to other applications led to expediting the passage of laundry through the industrial laundry and to expediting and simplifying the administrative processes. It also allowed for complete and accurate records keeping concerning individual pieces of laundry, which in turn led to reduction of losses and, ultimately, of the quantity of laundry which must be kept for each customer.

\section{DISCUSSION AND CONCLUSION}

In the previous sections in this paper, specifics of industrial laundry operation and issues faced by enterprises in this industry have been described. At the next step, technologies of Industry 4.0 have been identified which might be used for solving these issues. The case study presented in the previous section verified that at least two of these technologies automated identification and data capture and system integration - might be successfully used to make the industrial laundry processes more efficient.

As far as other Industry 4.0 technologies identified as appropriate for launch in a laundry operation are concerned, they have not been included in the presented case study. The authors of this paper believe, however, that they might be efficiently interconnected with the technologies already in use. The current machine equipment used in industrial laundries standardly provides network communication interface even now, so it would be possible to connect the machines into the Internet of Things. As each piece of laundry in the described operation is identified with a unique, machine-readable identifier, a complex cyber-physical system could be created in which each machine and each piece of laundry would be represented. Autonomous collaborative robots might be connected in such a system, assisting human workers with handling the laundry, or replacing them completely in some operations. This could result in a fully automated operation controlled through its virtual model in the IT system. "Smart Factory" which represents a central conception of Industry 4.0 [15], can exist in industrial laundries as well.

The paper was created under the ÉTA Program of the Technological Agency of the Czech Republic, project no. TL02000136 Knowledge-intensive services sector adaptation to the conditions of Society 4.0 . 


\section{References}

1. J. Vacek, L. Dvořáková, M. Černá, J. Horák, Z. Caha, V. Machová, Identifikace, analýza a hodnocení principio, postupů, metod a nástrojů pro adaptaci sektoru služeb na technické, ekonomické, sociální a environmentální podmínky Společnosti 4.0. (Plzeň: NAVA, 2019)

2. V. Mařík et al., Průmysl 4.0: Výzva pro Českou republiku. (Praha: Management Press, 2016)

3. E. Hofmann, M. Rüsch, Industry 4.0 and the current status as well as future prospects on logistics. Computers in Industry, 89, 23-34 (2017)

4. A. Rojko, Industry 4.0 Concept: Background and Overview. International Journal of Interactive Mobile Technologies (iJIM) 11, 77-90 (2017)

5. Y. Lu, Industry 4.0: A survey on technologies, applications and open research issues. Journal of Industrial Information Integration, 6, 1-10 (2017)

6. M. Polívka, L. Dvořáková, Využití automatické identifikace a sběru dat prostřednictvím radiofrekvenčních technologií $\mathrm{v}$ prostředí Průmyslu 4.0. Trendy $v$ podnikání, 9, 53-61 (2019)

7. T. Paschou, F. Adrodegari, M. Rapaccini, N. Saccani, M. Perona, Towards Service 4.0: a new framework and research priorities. Procedia CIRP, 73, 148-154 (2018)

8. L. Klerkx, D. Rose, Dealing with the game-changing technologies of Agriculture 4.0: how do we manage diversity and responsibility in food system transition pathways? Global Food Security, 24, 1-7 (2020)

9. G. Aceto, V. Persico, A. Pescapé, Industry 4.0 and Health: Internet of Things, Big Data, and Cloud Computing for Healthcare 4.0. Journal of Industrial Information Integration, 18, 1-13 (2020)

10. L. Barreto, A. Amaral, T. Pereira, Industry 4.0 implications in logistics: an overview. Proceedia Manufacturing, 13, 1245-1252 (2017)

11. K. Fukuda, Science, technology and innovation ecosystem transformation toward society 5.0. International Journal of Production Economics, 220, 1-14 (2020)

12. Ch. Leyh, T. Schäffer, K. Bley, S. Forstenhäusler, Assessing the IT and Software Landscapes of Industry 4.0-Enterprises: The Maturity Model SIMMI 4.0. In Ziemba, E. (Ed.) Information technology for management: new ideas and real solutions. (Cham: Springer International Publishing AG, 2017, pp. 103-119)

13. D. Inkerman, D. Schneider, N. L. Martin, H. Lembeck, J. Zhang, S. Thiede, A framework to classify Industry 4.0 technologies across production and product development. Procedia CIRP, 84, 973-978 (2019)

14. M. Herman, T. Pentek, B. Otto, Design Principles for Industrie 4.0 Scenarios. In Proceedings of the 2016 49th Hawaii International Conference on System Sciences (HICSS). Washington DC: IEEE Computer Society, 3928-3937 (2016)

15. V. Alcácer, V. Cruz-Machado, Scanning the Industry 4.0: A Literature Review on Technologies for Manufacturing Systems. Engineering Science and Technology, an International Journal, 22, 899-919 (2019)

16. S. Vaidya, P. Ambad, S. Bhosle, Industry 4.0 - A Glimpse. Procedia Manufacturing, 20, 233-238 (2018) 